\title{
The LIS Discipline or Retrieval Of Information: A Theoretical Viewpoint
}

\author{
Gholamreza Fadaie \\ Faculty of Psychology \& Education, University of Tehran, Iran
}

\author{
ghfadaie@ut.ac.ir
}

\begin{abstract}
In this artic le the author argues that LIS has suffered from lack of theoretical foundation. Recently many experts have tried to find a theoretical bas is for the subject. Nevertheless they are not satisfied yet and they have not achieved to a consensus. The author argues that it is because they stood on a wrong foot. Content analys is is the main approach to this paper. The author believes that there may be found a powerful theoretical basis for LIS through the retrieval of information and know ledge. The value of this argument is that LIS may obtain a good basis on subject, problems and principles. The author although has had a definition which is newly published (2008) now has changed his mind and proposed a new one. He argues that according to traditional teachings that every scientific discipline must bear a subject, objective and problems, with this new definition all are present and can be well justified.
\end{abstract}

Ke ywords: library and information science, information retrieval, theoretical foundation, meta science, information studies

\section{Introduction}

Although the concept of library is an old and historical one the librarianship and then documentation and information science are new concepts (Vickery, 2008b). By development of technology the LIS reached to its highest point in such a way that many misused the technology with LIS discipline. Some may argue that the beginning of library is book and the beginning of librarianship is classification (Maltby, in Miska, 1992) and the author argued that the foundation of library is classified knowledge storage and the foundation of librarianship is retrieval (Fada ie, 2004). This implies that the notion of (scientific) classification for retrieval precedes the library as a building (Fadaie, 2008a). And the aim of librarianship and then information science is to retrieve the information. Here by information the author means both information and knowledge.

Technology in recent years has changed every thing and served many disciplines especially librarianship (Vickery, 2008a). The best service of technology to LIS, to the author point, is that it awakened the scholars in this domain to think about the information itself and try to search for a

Material published as part of this publication, either on-line or in print, is copyrighted by the Informing Science Institute. Permission to make digital or paper copy of part or all of these works for personal or classroom use is granted without fee provided that the copies are not made or distributed for profit or commercial advantage AND that copies 1) bear this notice in full and 2) give the full citation on the first page. It is permissible to abstract these works so long as credit is given. To copy in all other cases or to republish or to post on a server or to redistribute to lists requires specific permission and payment of a fee. Contact Publisher@InformingScience.org to request redistribution permission. theoretical basis for this discipline. The growth of technology a long with the growth of publications did not allow the scholars especially librarians to think about theoretical basis for the ir profession. But nevertheless up to now although there have been many efforts they have not found a suitable foundation for this discipline. The author believes that defining the discipline was made on the wrong foot. 


\section{Basic Characteristics of a Discipline}

In traditional logic, as for Aristotle, every scientific branch must have subject, aim \& objective, and problems. Examples of some areas may be as follows:

- In Philosophy, the entity of world of reality is the subject and the aim and objective is to recognize the reality. Its problems in this field are definitions / recognizing of concepts such as unity, plurality, possibility, contingency, time and place, eternity and so on.

- In Physics the nature is the subject and the aim is to explore, recognize and use the physical laws by man, and the problems are distance, gravity, mechanics, dynamics, etc.

- In Chemistry, the subject is the micro nature, aim and objective is to facilitate the human's access to the objects, and the problems are how to synthesize or desynthesize many delicate things in the nature.

- Sociology is a science that deals with the people's treatment, the aim and its objective is to recognize the people's social activities, and the problems are social order $\&$ disorder, co-ordination and cooperation, social conflicts and so on.

- The subject in Religion as a discipline is to define the relationship between God and men, its aim is to define this relationship as well as the relationships of men in a divine order and its problems are men's individual or social duty and obligations.

- The subject of Zoology is animals, its aim and objective is to recognize them in order to make benefit from them, and its problems are animal's treatment, nutrition, training, diseases and so on.

- LIS subject (It will be discussed more in this article) is the men's need for retrieval of information, its aim and objective is to use the information for men' research and development and its problems are classification, indexing, knowledge organization and management, economics, users' behavior in need for information and so on.

\section{Some questions in this article:}

The methodology of this study is content analysis by which the author analyzes and compares the definitions made by experts. Some of basic questions in this artic le are as follows:

Is the name "LIS, or IS" the best designation for the field and do they transmit to the audience the suitable concept and meaning? Does LIS discipline in the tree of knowledge stands in the same rank as philosophy and philosophy or history of science? Is Knowledge science an appropriate name as proposed by a scholar? Is IS the same as science of information retrieval? Does Information retrieval relate directly to epistemology? Has technology affected on the basic principles of this field? Do the techniques of retrieval differ from one subject to another?

\section{Some critics}

Although the situation slightly has changed the reputation of librarians, in many countries such as Iran they used to hide their profession in a way (Fadaie, 2008a). It is because the name of librarianship does not convey the exact meaning that a scholar in this field knows or practices. As told by Christ $(1986 / 1365)$ librarian did not know how to deal with him rather than others. This was somehow because they thought that librarianship is mostly service oriented. Therefore, it is dependant on user's view. It means that service oriented jobs are usually subordinate to what people want, and there is no theoretical basis for the field itself. The influence of technology on LIS is so high that many confused the librarianship with information technology. This continuing change on the field is so great that some believe that LIS has a changing definition (Zins, 2006). 


\section{Library and Librarianship}

Many subject specialists have defined librarianship in the context of library. This is because the new idea of librarianship began to work after the explosion of information by the industrial revolution in Western countries. After a long debate and discussions by subject specialists some agreed that the library has two functions: one is education and the other is recreation. Nevertheless, up to now the discipline could not find any strong theoretical foundation (Mukuhrejee, 1999).

\section{Discussion}

Definition is very important in all aspects of the life. One who begins to do something must have a clear definition of what he does. Else s/he may step down in darkness, and is not aware of the result and may find challenges and finally be confronted with disaster. If the work is a social one with clear definition good communication takes place and planning will be possible. Every definition and specially the abstract ones must be comprehensive and restrictive. The definition must be based on the very intrinsic phenomena of the task and be originated from the very basic needs of human beings.

In LIS discipline the lack of clear definition and strong identity are the main challenges in front of the experts. Some may think that the librarian is merely a book keeper and its aim is to preserve the books in a place called library. Some think that it is a social activity (Fadaie, 2008a). Some say that the current definition of LIS in explaining the ability of the librarian is silent. Recently an expert (Zins, 2007a) carried on a comprehensive Delphi study on the subject to reach an acceptable definition. Nevertheless he reached to the idea that IS is an ever changing discipline (Zins, 2006). But the problem is that although change is a fact in the life (Vickery, 2008a) if the definition changes consciously it cannot be supposed as a discipline.

\section{My Previous Definition}

In my previous article I proposed a new definition for LIS and it was published in by issues on. A brief presentation (Fadaie, 2008a) of it which is called Meta Science and Information Studies (MSI, or MSIS) is as follows:

It is a discipline that deals with concise recognition of knowledge (classification) and considers the cross relationships (vertical \& horizontal) among the scientific and technical terms in order to maintain the exact and fast retrieval of information and know ledge.

As a definition, according to traditional logic must be comprehensive and restrictive, therefore, in the above definition, the word concise excludes the detailed explanation of knowledge as for the history and philosophy of know ledge as well as the pure philosophy. These two disciplines may discuss the information and know ledge in full detail; as what they are and how they were treated in the past. Cross relationship among the scientific and technical terms excludes the Linguistics and Communication, but partially includes the semantics, because the cross relationship among terms needs Semantics. The word special excludes the common terms such as ordinary, folklore and slang words. And the phrase exact and fast retrieval includes the information and knowledge management, information seeking behavior, information economics, bibliometrics and partially information technology and services (IT\&IS). This new approach which I called it as Meta science and information studies (MSIS) is a discipline which discusses the classification / indexing of know ledge and its relationships among all scientific terms, vertically and horizontally, and explores and explains the semantic relationships among terms to benefit users in retrieval. Therefore the problems of this discipline are to find out the most suitable classification scheme of knowledge for retrieval which defines these relationships in a way that facilitates the communication between users and documents. All common and sophisticated people live with the idea of classi- 
fication and retrieval, then, the library as a distinguished tool appears and stands significant to serve people. By this definition the relationship of information studies is stronger to Meta sciences than librarianship. Because one who recognizes knowledge can find to which discipline a piece of information belongs. According to this definition this new defined discipline gets its root from Philosophy, not Social sciences such as Communication or Education and so on.

Recently the author has changed his mind and he does not regard to this definition anymore. The reason is that Meta science although is relevant to this discipline it shares with other subjects such as philosophy, philosophy of science and may be history of science. Information studies, which is another part of the name of this discipline is rather vague. For information studies or information science there are many definitions (Zins, 2007b; Budd, 2002, 438). Besides in information studies the nature of information is discussed which may be out of the realm of LIS. In other words it may refer to the recognition of the information itself which is in the realm of epistemology. Also Meta science may cover the information studies. The table 1 below may show the relationships of Meta science more:

Table.1. Meta science or knowle dge (S/K)

\begin{tabular}{|l|l|l|l|}
\hline Epistemology & History of S/K & Philosophy of S/K & Retrieval of S/K \\
\hline
\end{tabular}

According to this chart all four discipline (Philosophy, History of science/know ledge, Philosophy of science/knowledge, and Retrieval of science/knowledge) are above other disciplines. There is a similarity between this chart and what Zins has illustrated. The difference between this chart and what Zins (2007c) advocates is especially in the forth box. He has brought the storage and retrieval and here the author prefers retrieval alone. The author thinks that retrieval has the storage in it while the opposite does not show that. That is many may store things or intellectual properties just for the sake of preservation or the considerations of ownership, and the retrieval may be a minor objective.

\section{How does Information Come to Us?}

The process of information and information making in human mind or soul is a matter of concern (Case, 2007, 40-3). When one encounters the reality s/he finds all things "in-form" ontologically and then s/he has to put them "in-form" epistemologically. The author has discussed the subject in his artic le called classification and world view (Fadaie, 2008b):

It is evident that from the earliest moment of life, when one encounters reality, s/he receives images, forms concepts, names them, creates definitions for them, and stores them in his/ her memory. But for recalling them, in actual recognition one must refer to the places, physically or mentally where they have been put before. It is easy to search when the things and concepts are few, but when the number and variety of things and concepts increase, one has to cluster them and put them in distinguished or coded places in order to retrieve them easily and correctly. So, this is the reason why we must accept that from the very beginning of our lives when we encounter the reality, we should organize our memory and therefore develop a sort of classification in order to be able to retrieve the information. This classification may be affected by the extent of our information and mostly by our way of looking at the world. To explain more, for example, when we want to mention blackness, or whiteness, as universals it is not possible unless we categorize/classify some similar things as blacks and whites. Then we derive the concepts of blackness and whiteness from them. 
When the universals came to being they are the same as data and information. Knowledge is composed by synthesizing the pieces of information (Zins, 2007c). We send the information to our memory for the sake of retrieval (Fadaie, 2008b). Figure 1 shows simple activity for IR.

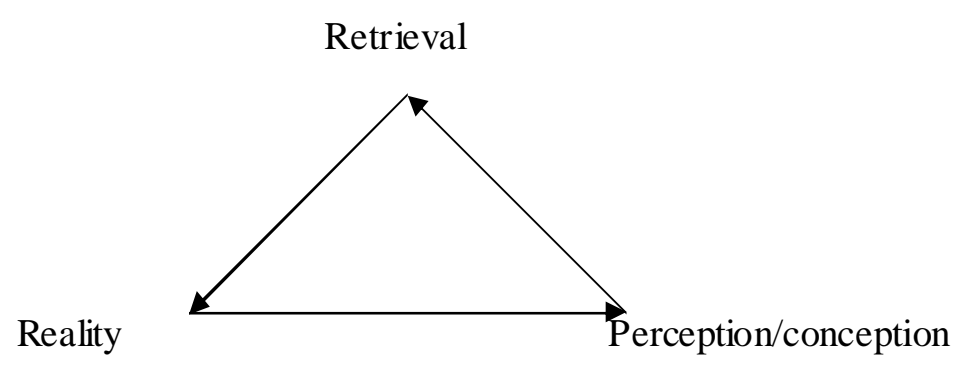

Figure 1. Simple shape of information retrieval

\section{The New ldea}

The new idea refers to retrieval as the basic element for the LIS. The science of information retrieval means the entire activities which may take place according to the definition of LIS. Science in LIS refers to how to retrieve the information that is human basic need. By new definition for this discipline there is no need to refer or explore the meaning of information because, the author believes it is in the realm of other fields such as epistemology. This discipline explores and retrieves the information whatever the meaning of information is (object, process, sign or symbol...). Therefore the new definition deals with information retrieval in the right form and time to satisfy the users in the best way possible. It differs from communication, although it uses it where and when needed. It makes use from other disciplines in the same way as other disciplines do. Figure 2 may have more.

\section{Basic elements in new definition}

As mentioned above for the other disciplines here we may define the basic elements for this discipline according to traditional logics. That is in this discipline, LIS or it is better to call it the Science of IR, the subject is retrieval of information and know ledge. Its aim \& objective is to improve the life by using the right information. It means that application of information and knowledge is necessary for now to manage the life and it is the building blocks for progress in the future. The major problems for IR discipline are as follows:

- Categorization such as clustering things and concepts.

- Organization such as classification schemes, indexing, thesaurus making...

- Bibliographic studies such as reference working, search methods, ...

- Knowledge management, management of information system, economics of information, $\ldots$

- Citations : authorship, co authorship,

- Information visibility such as bibliometry, scintomerty, ...

- User services: reference services, users' behavior and satisfaction, dissemination of information, information consultancy, philosophy of IR, ethics in IR...

- Information transmitters such as printed or digital documents, books, journals, libraries (traditional, hybrid or digital) and information centers (personal, local, national, historical)...

- $\quad$ IR \& technology

- IR \& publishing

- IR \& knowledge management

- IR \& domain analysis... 


\section{Human's information needs (application \& progress)}

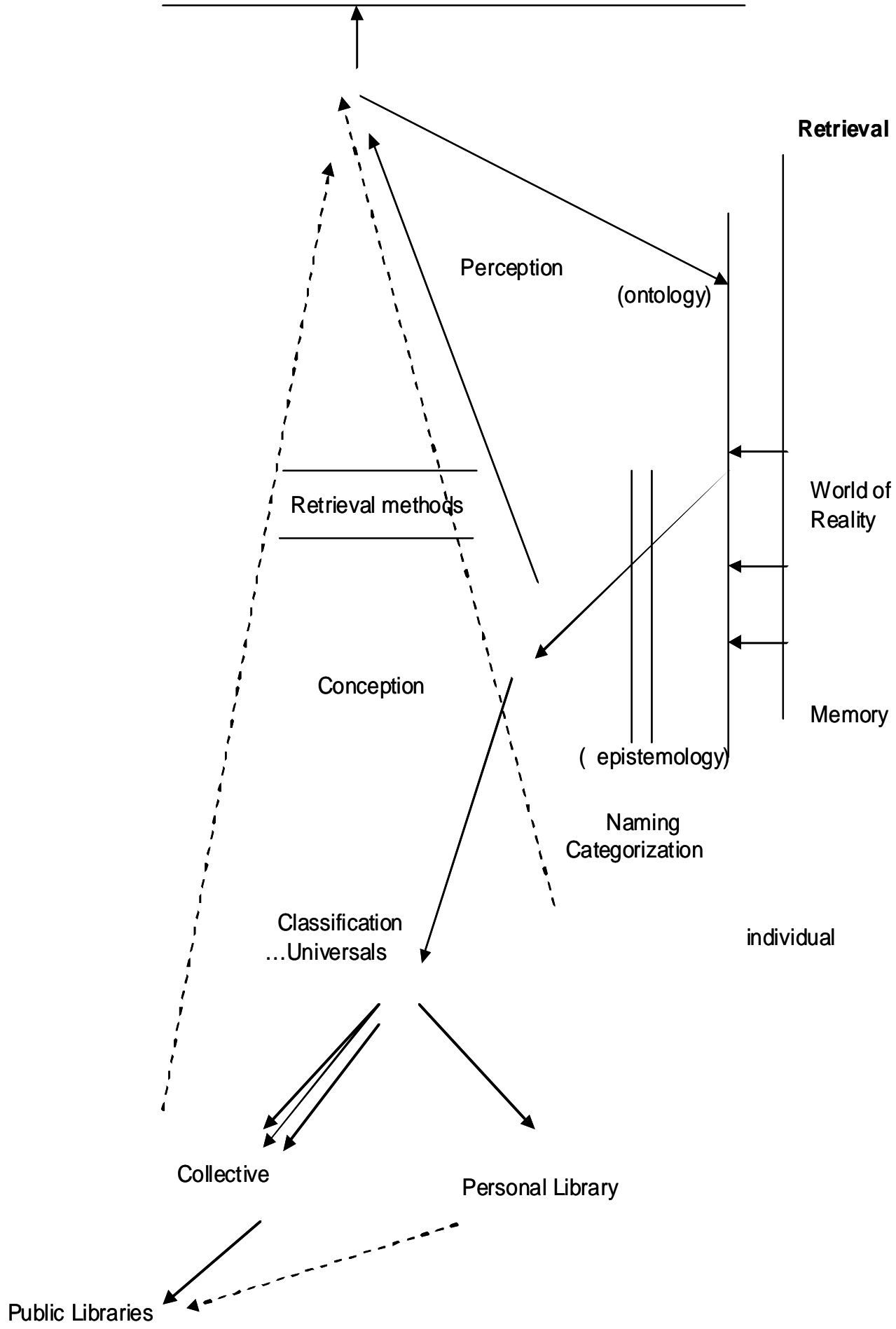

Figure 2. The state of perception, memory, libraries and retrieval 
According to above mentioned definition and its basic elements, the nature of LIS and now the Science of IR is always the same and the need for information and knowledge is not subject to change and its aim and objective is completely decisive. But its problems are subject to change. Because according to human's development in technology and the varieties of needs they may differ from time to time. Note that in this definition the two fields of publishing and know ledge management are definitely related to this discipline. Because if the so called librarian and information specialist are present in publishing software activities they can manage the publication in such a way that the information can be easier retrieved due to better indexing and classification. Better consulting with the authors to write or mange their writing in such a way to attract better audiences is also a main consideration for IR specialists. Another field is the field of knowledge management (KM). KM is a part of LIS, or IR discipline. In this context information or knowledge management is a part of the science of IR. The managers and decision makers in order to decide correctly and act decisively need to have the latest and newest information and knowledge in appropriate time. This great task is certainly done by information specialists and retrievers. Another fact is that retrieval of information speaks out in doma in analysis. The indexers and the users can interact only when they are familiar with the context they are working with. Figure 3 may have more.

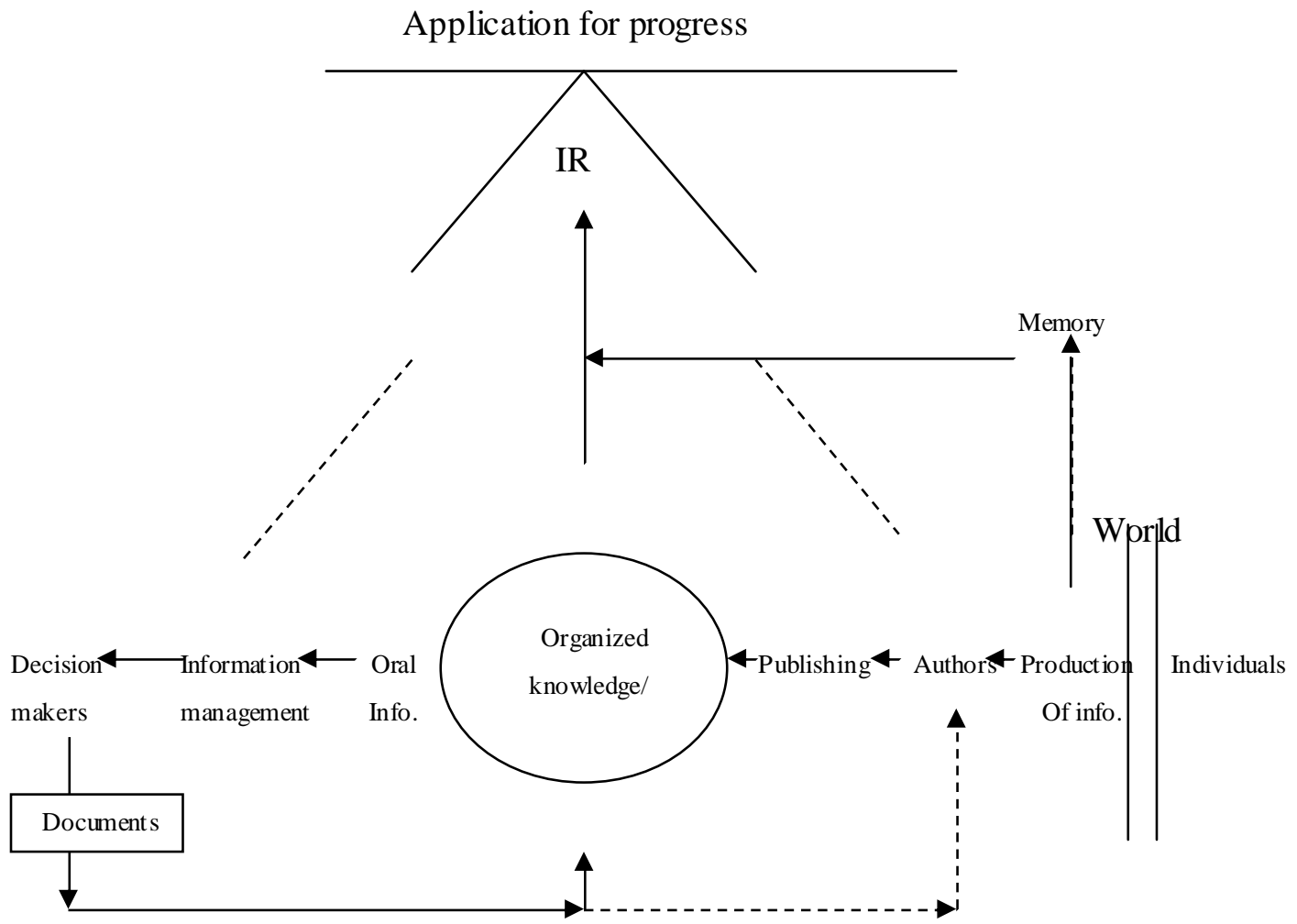

Figure3. The scope of IR which is more complicated

\section{Comprehensive and restrictive}

According to this new definition the author thinks that the LIS has got its right definition and can stand upright between other disciplines. It means that the definition of retrieval of information and know ledge in a best way possible is decisive, comprehensive and restrictive. It is the science of retrieval of information and know ledge; it helps all disciplines and gets help from them, too. 


\section{Does IR Tend to Information Production?}

As told before the task of IR usually comes after the information production. That is men for development try to explore, create, and find new things or new ways to apply in their life. The production of information is not in the core duty of LIS discipline though the scholars can investigate for their own curios ity. Also IR works well and in appropriate way when domain is clear. In an unknown or vague field retrieval does not answer well and both indexer and user may have challenges and may not feel well. Figure 4 may show it better.

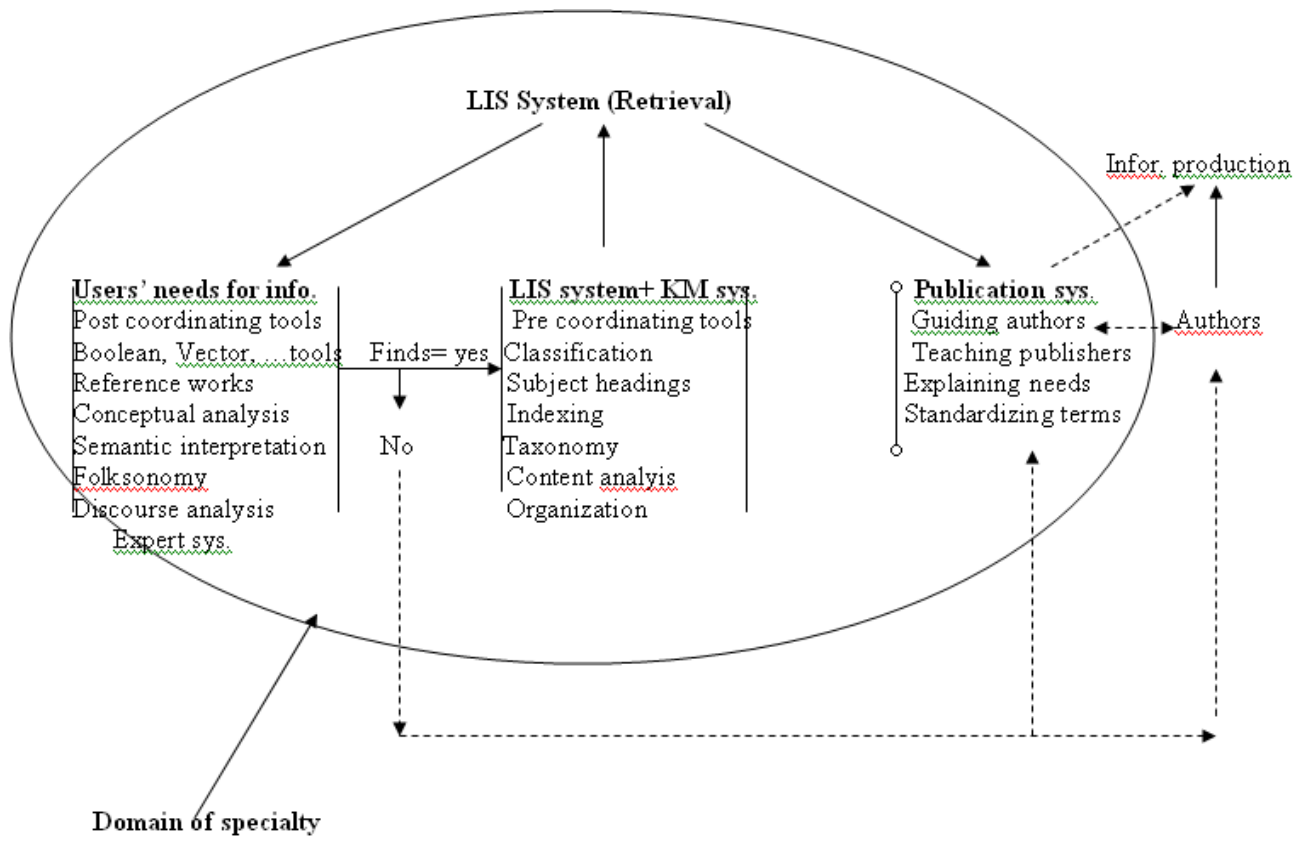

Figure 4. The scope of LIS (retrieval) sys tem and its subdivisions with emphasizing on domain of specialty

\section{Conclusion}

LIS is very important but suffers from the lack of theoretical basis. It is mostly because we stood on a wrong foot. We have tried to define librarianship by library as a building, while the library as a building has been a strong and unique manifestation of human basic need for information and know ledge (Fadaie, 2008a). The explosion of information in recent century and especially in recent decades and years forced the experts to search for a new identity. For this reason many scholars in LIS discipline tried to find a new definition through defining the nature of information. Although it helped a lot, I think they have exaggerated for the result. The nature of the information and know ledge although are important they are not originally inside the duty of LIS as a discipline. It relates to the epistemology. The Science of IR, basically does not tend to the nature of information, it shows the basic human need for knowing.

This new defined discipline stands in the upper class in the same rank as epistemology; it is not in the realm of sociology, education, and so on. It seems to be a Meta science. By this definition the subject is stable and does not change during the time and according to other disciplines, but the problems may change and increase by the time and technology may bring some new problems and opens some new areas. Dialogue, communication and also information seeking (Budd, 2001) help reference workers/users to define the need and they are as mechanism for preparation of the 
user to find out what s/he wants. They are outside of the IR task and are before the task of IR begins.

\section{References}

Budd, J. M. (2001). Information seeking in theory and practice; Rethin king public services in libraries. Reference \& User Services Quarterly, 40(3).

Budd, J. M. (2002). Jesse Shera, Socialogist of knowledge. The Library Quarterly, 72(4).

Case, D. O. (2007). Looking for information (2nd ed.). NY: Academic Press.

Christ, J. M. (1365/1986). Mabani-y-Ketabdari [The foundations of librarianship]. (Translated by Asad allah A zad). Mashad, Astan Quds, Razavi,.

Fadaie Araghi, G. (2004). A dynamic look towards classification and retrieval. Cataloging and Classification Quarterly, 38(1).

Fadaie Araghi, G. (2008a). In search of new identity for LIS discipline, with some reference to Iran. Issues in Information Science and Information Technology, 5, 499-511. Retrieved from http://proceedings.informingscience.org/InSITE2008/IISITv5p499-511Fadaie409.pdf

Fadaie Araghi, G. (2008b). The influence of classification on worldview and epistemo logy. Proceedings of the Informing Science \& IT Education Conference (InSITE) 2008, pp. 1-13. Retrieved from http://proceedings.informingscience.org/InSITE2008/InSITE08p 001-013Fadaie410.pdf

Miksa, F. L. (1992). The concept of the universe of knowledge and the purpose of LIS classification. In N.J. Williams on \& M. Hudon (Eds.), Classification research for knowledge representation and organization, Proceedings of the $5^{\text {th }}$ International Study Conference on Classification Research. Canada, 1991., London: Elsevier. pp. 89-100.

Mukohrejee, A. K (1999). The history and philosophy of librarianship. (Translated into Persian by Assad allh Azad.) Mashhad: Astan Qods Razavi

Vickery, B (2008a). Thinking about change. Retrieved fro mhttp://www.lucis.me.uk/change.htm\#start

Vickery, B (2008b). What general Information theory do we need? Retrieved from http://www.lucis.me.uk/infotheory.htm\#start

Zins, C. (2006). Redefining information science: fro m "information science" to "knowledge science". Journal of Documentation, 62(4).

Zins, C. (2007a). Classification scheme of information science: 28 scholars map the Field. JASIST, 58(5).

Zins, C. (2007b).Conception of Information Science. JASIST, 58(3).

Zins, C. (2007c). Conceptual approaches for defin ing data, information, and knowledge. JASIST. DOl:10 $1002 / a s i$

\section{Biography}

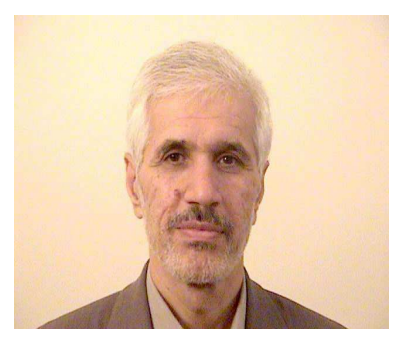

Gholamreza Fadaie, Ph.D in LIS is associate professor in Faculty of Psychology \& Education, University of Tehran, Iran. He is 64 years old and has about 14 books and more than 30 artic les in Persian. Also he has several articles in English and Arabic. Four of his English articles have been published in Cataloging and Classification Quarterly journal in 2004 and 2005. He has some new idea about classification and philosophy of LIS. E-mail: ghfadaie @ ut.ac.ir 